\title{
Evaluation of the safety parameters for permitted explosive type emulsion
}

\author{
Ilie-Ciprian Jitea ${ }^{1 *}$, Daniela Carmen Rus ${ }^{1}$, Cristian Rădeanu ${ }^{1}$, and Dragoș Gabriel \\ Vasilescu ${ }^{1}$
}

${ }^{1}$ National Institute for Research and Development in Mine Safety and Protection to Explosion INSEMEX Petrosani, Department of Safety of Explosion and Pyrotechnic Articles, G-ral V. Milea Street 32-34, Petrosani, Romania

\begin{abstract}
When preparing a permitted explosive recipe an energy or an explosive heat is considered, which should ensure the detonability of the system and at the same time a power that satisfies the purpose for which it will be used, under the conditions of firedamp hazardous mines. The safety parameters for the explosive charges used in the firedamp hazardous mines are decisive, in order to ensure the safety and health requirements at work together with the efficient performance of the blasting operation. The permitted explosive type emulsion is recommended to be used in underground mines, open pit mines as a special methane explosive and can be used where a coal dust and/or methane explosion hazard exists can be loaded into dry and wet blasting holes and it can be used for mechanical loading. The permitted explosive type emulsion is a Detonator-sensitive explosives that can be reliably initiated in an unconfined state by a No. 8 strength detonator it have safety handling characteristics because of the relatively low sensitivity to friction, shock and impact. Technological changes due to the change of suppliers of certified explosives for civil use for underground use in the firedamp hazardous mines, involve reassessing the safety and efficiency of the loads made with these products, which have not been tested and evaluated for the conditions from the Jiu Valley mines.
\end{abstract}

\section{Introduction}

Testing of firedamp-proof explosives for civil use for their safe use in potentially explosive atmospheres by checking the safety of methane and coal dust in order to ensure continued satisfaction of the requirements of Directive 2014/28 / EU Annex II, GD no. 197/2016 Annex 2, as well as from the Normative Document of the product. Explosives are materials and articles considered to be explosive under the "United Nations Recommendations on the Transport of Dangerous Goods" and which fall into Class 1 of these Recommendations. The firedamp-proof explosive is used for underground works and is safety against methane (property of explosives not to ignite by detonating flammable atmosphere / explosive air methane, in a concentration of $8-10 \%$ vol. CH4) and coal dust (property of explosives, not

\footnotetext{
*Ilie-Ciprian Jitea: ciprian.jitea@insemex.ro
} 
to ignite by detonating the flammable / explosive atmosphere, air - methane in a concentration of $3.5-4.5 \%$ vol. CH4 - coal dust $330 \mathrm{~g} / \mathrm{m}^{3}$ in suspension and $50-150 \mathrm{~g}$ in the mortar channel) $[1,2,3,4,5]$.

\section{Measuring and testing equipment / materials}

The tunnel for testing firedamp-proof explosives have a cylindrical shape with a diameter of $1.5 \mathrm{~m}$ made of steel sheet of approx. $10 \mathrm{~mm}$, with a section of $1.76 \mathrm{~m}^{2}$ and a total length of $15 \mathrm{~m}$. The tunnel has an explosion chamber with a volume of $10 \mathrm{~m}^{3}$ and an expansion chamber with a volume of $21 \mathrm{~m}^{3}$ (Figure 1).

The explosion chamber is provided with the following:

- Device for gripping paper or polyethylene foil to seal the explosion chamber during testing;

- Devices for fixing bags with the coal dust;

- Fan for homogenizing the air - methane mixture;

- Fan for tunnel ventilation after each test;

- Methane supply pipe for the explosion chamber;

- Hose for connecting portable equipment for measuring methane concentration;

- Terminals with short circuit key for connecting the rheophores in the tunnel and the outdoor blasting cable;

- Ventilation column sealing cover.

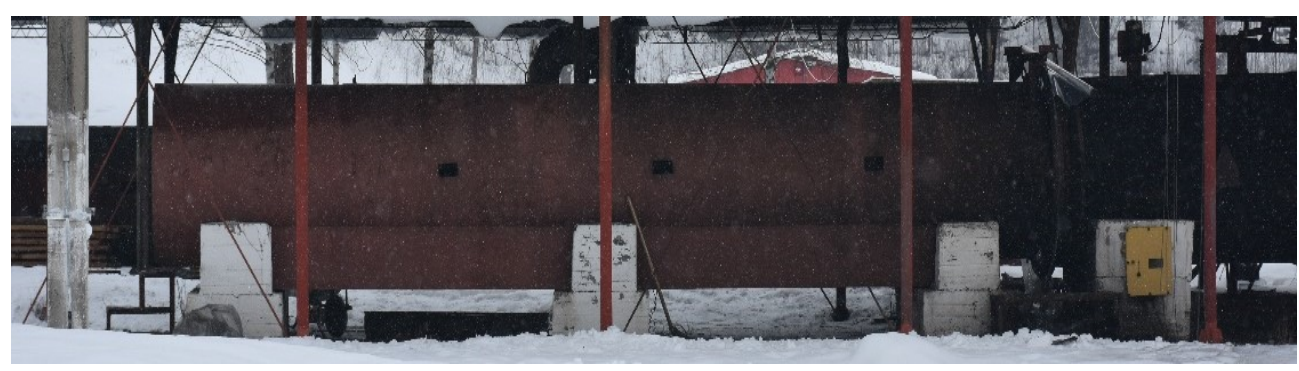

Fig.1. Tunnel for testing firedamp-proof explosives provided with central channel

The mortar with a central channel: it is a cylindrical steel block with a length of 2,200 $\mathrm{mm}$ provided with a central channel with a diameter of $50 \mathrm{~mm}$ and a length of $1,500 \mathrm{~mm}$. Firedamp-proof safety explosives are being positioned for the test in this mortar.

Apparatus for measuring methane concentration (methanometers, interferometers, etc.) with the measuring range $0-10 \% \mathrm{CH} 4$.

The methane gas has to have the following characteristics:

- Minimum 96\% methane;

- Maximum 4\% other homologous methane hydrocarbons;

- Not to contain traces of hydrogen.

The Coal dust is prepared according to operational procedure PO-06 "Preparation of coal and determination of coal dust granulation, ash content, volatile matter content and coal moisture", with the following characteristics:

- Ash content: maximum 10\%;

- Volatile matter content: minimum 30\%;

- Fineness: $80 \%$ passage through sieve with square meshes of $0.071 \mathrm{~mm}$ and $100 \%$ passage through sieve with square meshes of $1 \mathrm{~mm}$.

Electric detonators with copper tube:

- Instantaneous detonator or step 0;

- Detonators with a half - second delay, step 2 or step 0. 
Spoon (cylindrical device cut after generators) of copper, aluminum or PVC for loading explosive cartridges into mortar with central channel.

\subsection{Preparation of samples for methane safety verification of firedamp-proof explosives}

The preparation of the samples is done on the table in the manipulation room of the observation post as follows:

- Testing of firedamp-proof safety explosives is done in the form of cartridges as delivered by the manufacturer (Figure 2);

- The size of the explosive charge in a test is that established by the product standard;

- The explosive cartridges is place on the spoon (device made especially for this purpose);

- The cartridges are placed on the spoon to be inserted in the mortar hole placed towards;

- The last cartridge is initiated with an instantaneous electric detonator (or stage 0) the rheophores are hold as supplied by the manufacturer (short-circuited or fully insulated).

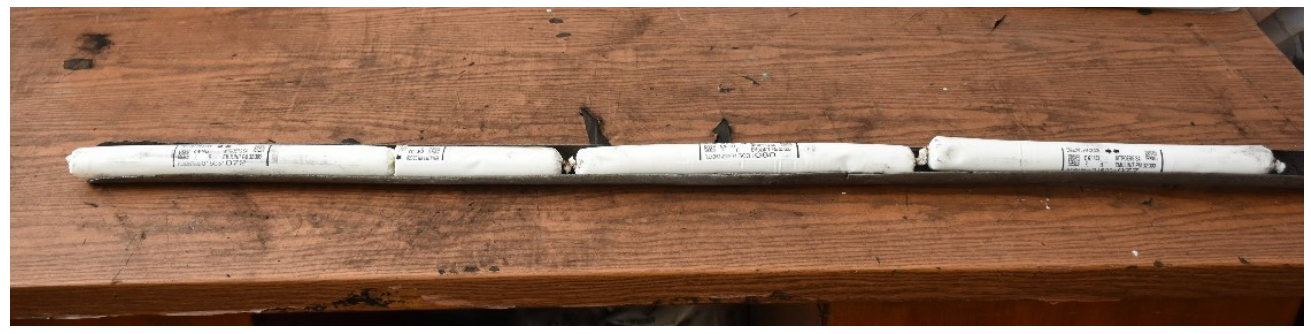

Fig.2. Emulsion-type explosive cartridges prepared for air-methane mixing test

\subsection{Preparation of samples for safety testing of methane and coal dust of firedamp-proof safety explosives}

- The test of firedamp-proof safety explosives is done in the form of cartridges as delivered by the manufacturer;

- The size of the explosive charge on a test is that determined by the product standard;

- The explosive cartridges are places on a spoon (device specially made for this purpose) where previously coal dust has been placed as follows: on the first 2 tests $50 \mathrm{~g}$ each, on the third test $75 \mathrm{~g}$, on the fourth test $100 \mathrm{~g}$ and at the fifth test $150 \mathrm{~g}$. The amount of powder is measured with a measure of $50 \mathrm{~g}$ of powder (Figure 3 ).

- The cartridges are inserted in the mortar hole placed end to end;

- To make the coal dust in suspension, $1 \mathrm{~kg}$ of cold dust / bag is inserted in three paper bags. - To spread the dust, a quantity of approx. $12.5 \mathrm{~g}$ of firedamp-proof safety explosive is inserted into each bag, which is primed with an instant electric detonator (or step 0).

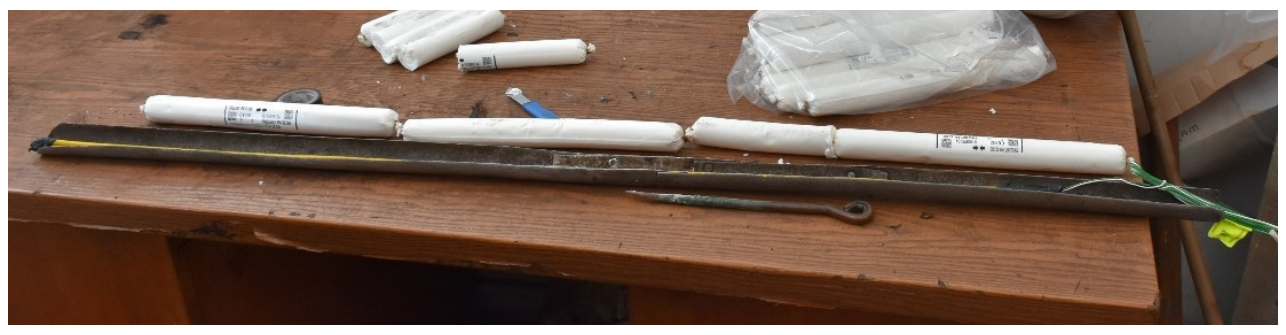

Fig.3. Preparation of emulsion-type explosive cartridges for testing in air-methane coal dust mixture 


\subsection{Testing of firedamp-proof safety explosives in air - methane atmosphere}

The working method for checking methane safety is as follows:

a) The test site is prepared (the tunnel terminals are cleaned, the methane tube are connected to the methane pipe via the pressure reducer and hoses), the atmospheric temperature is measured.

b) The explosive cartridges are inserted into the mortar channel with the help of a spoon (the device specially made for this purpose), so as to form a continuous charge.

c) The primed cartridge is inserted last in the mortar channel (previous priming).

d) The test is performed without bursting the load.

e) The temperature in the tunnel is measured and if $t<-50^{\circ} \mathrm{C}$ the tunnel is heated by performing a methane ignition with a volumetric concentration $\mathrm{CH} 4=8.5-10 \%$ or $3.5 \div$ $4.5 \% \mathrm{CH} 4$ and coal dust. At $+30^{\circ} \mathrm{C}$, the explosion chamber must be cooled by spraying the outer wall with water.

f) After placing the load in the mortar, the detonator rheophores are connected to the connection terminals that have previously been short-circuited.

g) The paper screen or polyethylene foil is pulled after the blaster have left the tunnel.

h) The paper screen or polyethylene foil is fix with the sealing ring, thus separating the explosion chamber from the expansion chamber.

i) The flammable / explosive air - methane atmosphere is created in the explosion chamber. With the help of the fan mounted in the tunnel, the mixture is homogenized for at least 1 minute.

j) The methane concentration is measured with a methanometer or interferometer, immediately after homogenization, the methane concentration must be $8-10 \%$ by volume. If it is found that the methane is not in the proper concentration in the explosion chamber, it is adjusted by introducing either air or methane and checking the methane concentration each time. After each methane or air introduction operation, the mixture is homogenized for at least 1 minute.

k) The short-circuit key of the tunnel terminals is unscrew.

l) The personnel are withdraw from the safety zone and the warning signal are given.

$\mathrm{m}$ ) The explosion is triggered from the observation post with the help of a blasting machine in firedamp- proof construction after the short connection of the shooting cable to the observation post has been previously loosened.

$\mathrm{m})$ The behavior of the explosive is observed during the tests through the side windows of the expansion chamber (presence / absence of flame). At the same time, the thermal effects of the explosion on the rheophores of the staples and of the polyethylene paper or foil with which the explosion chamber was sealed are also monitored.

n) The "Register of primary evidence for the safety check against methane and coal dust of firedamp-proof safety explosives" is completed.

o) The operations are repeated for a new test after the tunnel has been ventilated for at least 5 minutes.

p) Five tests are performed.

\subsection{Testing of firedamp-proof safety explosives in the atmosphere air - methane - coal dust}

The working method for checking the safety of methane and coal dust is as follows:

a) Prepare the test site as in this procedure.

b) The coal dust bags are suspend, prepared according to the present procedure, and by their fixing devices located in the tunnel explosion chamber. The amount of coal dust in the 
three paper bags ensures, after spreading, a suspension concentration of $330 \mathrm{~g} / \mathrm{m}^{3}$ which corresponds to the stoichiometric concentration.

c) The explosive cartridges and the coal dust are introduced into the mortar channel, with the help of the spoon (the device specially made for this purpose) of this procedure.

d) The test is performed as in the proviso that the volumetric concentration of methane must be $3,5-4,5 \%$ vol.

e) 5 successive tests are performed [6].

\section{The results of the emulsion type firedamp-proof explosive test}

Expression of safety results against methane and coal dust of emulsion-type firedamp- proof safety explosives, delivered in the form of cartridges with a mass of $300 \mathrm{~g}$, a diameter of 32 $\mathrm{mm}$ and a length of $300 \mathrm{~mm}$, packed in transparent polyethylene are expressed by ignites or doesn't ignites the flammable / explosive mixture in which the explosive was tested. Safety against explosive air-methane atmosphere verified at the test tunnel with the load of $1,050 \mathrm{~g}$ explosive in mortar with central channel, in methane atmosphere (Table 1).

Table.1. Methane concentration $8 \square 10 \%$ volume

\begin{tabular}{|c|c|c|c|c|}
\hline \multirow{2}{*}{ No. crt. } & \multirow{2}{*}{$\begin{array}{c}\text { Methane } \\
\text { concentration } \\
(\%)\end{array}$} & \multicolumn{2}{|c|}{ Temperature $\left({ }^{\circ} \mathrm{C}\right)$} & \multirow{2}{*}{$\begin{array}{l}\text { Test result: } \mathrm{A}=\text { ignites } \\
\mathrm{NA}=\text { doesn't ignites }\end{array}$} \\
\hline & & Atmospheric & $\begin{array}{c}\text { In explosion } \\
\text { chamber }\end{array}$ & \\
\hline 1. & 9,40 & $+2^{\circ} \mathrm{C}$ & $+10^{\circ} \mathrm{C}$ & NA \\
\hline 2. & 9,70 & $+2^{\circ} \mathrm{C}$ & $+10^{\circ} \mathrm{C}$ & NA \\
\hline 3. & 9,10 & $+3^{\circ} \mathrm{C}$ & $+11^{\circ} \mathrm{C}$ & NA \\
\hline 4. & 9,00 & $+3^{\circ} \mathrm{C}$ & $+11^{\circ} \mathrm{C}$ & NA \\
\hline 5. & 9,70 & $+3^{\circ} \mathrm{C}$ & $+10^{\circ} \mathrm{C}$ & $\mathrm{NA}$ \\
\hline
\end{tabular}

Safety against explosive atmosphere air-methane-coal dust checked at the test tunnel with the load of 1,050 $\mathrm{g}$ explosive in mortar with central channel, in atmosphere of coal dust (330 $\mathrm{g} / \mathrm{m}^{3}$ in suspension and $50 \square 150 \mathrm{~g}$ in the mortar channel) and methane (Table 2).

Table.2. methane concentration 3,5 $\square$ 4, $5 \%$ volume

\begin{tabular}{|c|c|c|c|c|c|c|}
\hline \multirow{2}{*}{$\begin{array}{c}\text { Nr. } \\
\text { crt. }\end{array}$} & $\begin{array}{c}\text { Methane } \\
\text { concentra } \\
\text { tion } \\
(\%)\end{array}$ & $\begin{array}{c}\text { Coal dust } \\
\text { in mortar } \\
\text { channel }\end{array}$ & $\begin{array}{c}\text { Coal dust suspended } \\
\text { in the air in the blast } \\
\text { chamber }\left(\mathrm{g} / \mathrm{m}^{3}\right)\end{array}$ & \multicolumn{2}{|c|}{ Temperature $\left({ }^{\circ} \mathrm{C}\right)$} & $\begin{array}{c}\text { Test result: } \mathrm{A}= \\
\text { ignites NA }= \\
\text { doesn't } \\
\text { ignites }\end{array}$ \\
\hline 1. & 4,00 & 50 & 330 & $\begin{array}{c}\text { Atmosp } \\
\text { heric }\end{array}$ & $\begin{array}{c}\text { In } \\
\text { explosion } \\
\text { chamber }\end{array}$ & \\
\hline 2. & 4,20 & 50 & 330 & $+7^{\circ} \mathrm{C}$ & $+14^{\circ} \mathrm{C}$ & NA \\
\hline 3. & 4,00 & 75 & 330 & $+7^{\circ} \mathrm{C}$ & $+14^{\circ} \mathrm{C}$ & NA \\
\hline 4. & 3,90 & 100 & 330 & $+14^{\circ} \mathrm{C}$ & NA \\
\hline 5. & 4,20 & 150 & 330 & $+8^{\circ} \mathrm{C}$ & $+14^{\circ} \mathrm{C}$ & NA \\
\hline
\end{tabular}




\section{Conclusions}

When using a firedamp-proof safety explosive, an energy or an explosive heat is taken into account to ensure the detonability of the system and at the same time an appropriate power to satisfy the purpose for which it will be used.

The activity contraction of underground coal mining has meant that there are fewer and fewer producers of firedamp-proof explosives at European level. For years in the mines of the Jiu Valley, firedamp-proof explosives of powder type have been used, now the transition is made to firedamp-proof safety explosive type emulsion.

The laboratory tests showed that the firedamp-proof safety explosive type emulsion corresponds in terms of safety characteristics specific to the Mines in the Jiu Valley, not igniting the potentially explosive atmosphere.

The transition to the safety explosive type emulsion will continue through a test program for the safe use of the explosive in the mining works at the Jiu Valley Mining Exploitations.

In order to ensure the technical-scientific conditions for the implementation of an adequate system for evaluating the parameters of influence of the firedamp-proof atmosphere regarding its ignition by the emulsion-type firedamp-proof explosives, the test method of these types of products was documented, elaborated and validated.

\section{References}

1. Bauer, I.A., Calder, P.- New guidelines in the field of explosives, drilling and blasting - C.I.M. Bullettin 2/1974.

2. Becut, S., The evolution and the current stage in the elaboration of the safety explosives and of the initiation means for the methane mines, Doctoral report no. 1, February 2004.

3. Holmberg, R. - Explosives and Blasting Techniquer - Swets \& Zeitlinger B.V., Lisse, The Netherlands, 2003.

4. Jitea, I., C., Lupu, C., (2014), Procedure for metal cutting using explosives, with low environmental impact, Environmental Engineering and Management Journal, June 2014 Vol.13 No.6, pp.14591462, ISSN $1582-9596$.

5. Attila Kovacs, Gabriel Dragos Vasilescu, Edward Gheorghiosu, Daniela Rus, Ciprian Jitea, (2017), Improvement of security measures during the use of explosives in firedamp hazardous mines, Environmental Engineering and Management Journal, June 2017, Vol.16, No. 6, 1295- 1299.

6. Test procedure PI - 81 Safety check for methane and coal dust of the firedamp-proof safety explosives. 